\title{
Widespread pain in axial spondyloarthritis: clinical importance and gender differences
}

\author{
Thijs Willem Swinnen ${ }^{1,2,3^{*}}$ (D), René Westhovens ${ }^{1,2}$, Wim Dankaerts ${ }^{3}$ and Kurt de Vlam ${ }^{1,2}$
}

\begin{abstract}
Background: There is a remarkable lack of detailed knowledge on pain areas in axial spondyloarthritis (axSpA), and their clinical relevance is largely unknown. Pain area may reflect local disease processes, but amplification of nervous system signalling may alter this relationship. Also, gender differences in pain area may exist in axSpA, possibly confounding disease activity outcomes. Therefore, we firstly detailed pain locations in axSpA and evaluated gender differences. Secondly, we explored the relationship of regional pain definitions with clinical outcomes. Finally, we explored the role of pain area in the assessment of disease activity.

Methods: Body charts informed on the presence of axial, peripheral articular and non-articular pain in 170 patients (108 men, 62 women) with axSpA. Multivariate Odds Ratios (ORs) were used to compare genders. General linear models were used to explore clinical differences in disease activity (Bath Ankylosing Spondylitis Disease Activity Index [BASDAI]), activity limitations (Bath Ankylosing Spondylitis Functional Index [BASFI]), fear of movement (Tampa Scale for Kinesiophobia 11 -item version [TSK-1 1]), anxiety (Hospital Anxiety and Depression Scale subscale anxiety [HADS-A]) and depression (HADS subscale depression [HADS-D]) between four subgroups classified by widespread non-articular pain (WNAP+/-) and physician global assessment of disease activity (PGDA+/-) $(p<.05)$. Principal Component Analysis (PCA) was performed to explore gender differences in the structure of disease activity.

Results: Axial thoracic pain was least prevalent (lumbar, 74.4\%; cervical, 47.6\%; cervicothoracic, 47.6\%; thoracic, 32.4\%), but it was about three times more likely in women $(\mathrm{OR}, 2.92 ; p=.009)$. Axial cervicothoracic junction pain spread more diffusely in women (OR, 2.48; $p=.018)$. Women exhibited a two- to threefold increased likelihood of widespread axial $(\mathrm{OR}, 3.33 ; p=.007)$ and peripheral articular (OR, 2.34; $p=.023)$ pain. A subgroup of WNAP+/PGDA- combined with low PGDA (27\% of all patients) was associated with worse BASFI, BASDAI, HADS-A and HADS-D in men and worse TSK-11 and HADS-A in women $(p<.05)$. Disease activity outcomes showed a two-factor structure in women but not in men.
\end{abstract}

Conclusions: In patients with axSpA, the location and spread of pain was different between genders and was related to worse clinical status. On the basis of pain area and PGDA, clinical subgroups exhibiting a remarkably distinct health status were identified. Outcome instruments such as BASDAl should acknowledge gender differences to ensure structural validity.

Keywords: Ankylosing spondylitis, Widespread pain, Anxiety, Disability, Inflammation, Depression, Body chart, Gender differences

\footnotetext{
* Correspondence: thijs.swinnen@uzleuven.be

Wim Dankaerts and Kurt de Vlam shared senior authorship.

${ }^{1}$ Division of Rheumatology, University Hospitals Leuven, Herestraat 49, 3000

Leuven, Belgium

${ }^{2}$ Skeletal Biology and Engineering Research Center, Department of Development and Regeneration, KU Leuven, Herestraat 49 box 7003/13, 3000 Leuven, Belgium Full list of author information is available at the end of the article
}

(c) The Author(s). 2018 Open Access This article is distributed under the terms of the Creative Commons Attribution 4.0 International License (http://creativecommons.org/licenses/by/4.0/), which permits unrestricted use, distribution, and reproduction in any medium, provided you give appropriate credit to the original author(s) and the source, provide a link to the Creative Commons license, and indicate if changes were made. The Creative Commons Public Domain Dedication waiver (http://creativecommons.org/publicdomain/zero/1.0/) applies to the data made available in this article, unless otherwise stated. 


\section{Background}

Disease processes in axial spondyloarthritis (axSpA) involve tissue inflammation seen as enthesitis, synovitis and bone marrow oedema, as well as structural damage in the form of erosion, fat metaplasia/backfill and bone formation (sclerosis, ankylosis) [1, 2]. Spinal articular features typically occur at intervertebral corners and end-plates, zygapophyseal, and costovertebral and costotransverse joints, as well as at spinal ligament insertions $[2,3]$. Asymmetrical mono- or oligoarthritis and enthesitis may add peripheral aspects to the predominant axial disease presentation [2]. Extra-articular features such as psoriasis, anterior uveitis or inflammatory bowel disease further illustrate the systemic nature of axSpA [2]. Although the exact aetiology of axSpA is largely unknown, a complex interplay between genetics (e.g., HLA-B27 [2]), biomechanical stress within the enthesis organ [4], gut bacterial dysbiosis [5] and several dysfunctional immune-competent cells (e.g., innate lymphoid group 3 cells [6]) may elicit auto-inflammation driven by key cytokines tumour necrosis factor (TNF)- $\alpha$, interleukin (IL)-17 and IL-23 [7].

Cardinal clinical signs and symptoms of axSpA include inflammatory pain, stiffness and impaired mobility in the axial region and peripheral joints. To a large extent, these features are thought to reflect adaptive pain-motor mechanisms associated with inflammation and consequences of bone formation associated with the disease $[8,9]$. To capture these local tissue processes, the Assessment in SpondyloArthritis international Society (ASAS) expert group endorsed classification and response (ASAS20, ASAS40, ASAS 4/5) criteria, as well as disease activity (Bath Ankylosing Spondylitis Disease Activity Index [BASDAI], Ankylosing Spondylitis Disease Activity Index [ASDAS]) and spinal mobility (Bath Ankylosing Spondylitis Metrology Index [BASMI]) scales in axSpA [2]. These mainly include self-reported numerical rating scales used to assess axial/peripheral pain intensity and spinal stiffness duration, but they also include clinical examination findings (e.g., joint effusion) and metrology using a tape measure [2].

Although useful for research, the mere focus on inflammation in the assessment of body structures and functions as proposed by ASAS may have pitfalls in clinical practice. Firstly, nociceptive/mechanical [10], neuropathic [11] or dysfunctional [12] pain mechanisms may complicate the clinical picture in axSpA and concurrently may influence pain intensity or stiffness duration scales. For example, ongoing low-grade or intense episodes of inflammation in axSpA likely induce a bottom-up amplification of neural signalling in the central nervous system that leads to pain hypersensitivity and to the spread of pain in a broader area, a process known as central pain plasticity (central sensitization)
[13]. Also, psychological factors have been shown to exert top-down effects on disease activity estimates in axSpA [14]. Clinically, these pain mechanisms may translate to widespread pain, a feature seen in about $2-34 \%$ of patients with axSpA $[12,15,16]$. Secondly, ASAS outcome instruments including cut-offs for disease status or treatment response assume homogeneity in the axSpA population. Recently, gender differences in disease activity items such as higher reported pain intensity [17] or lower spinal mobility measures [18] have increasingly been observed in axSpA. Because cut-off levels might impact treatment decisions, this issue cannot be underestimated.

As a first step to improve the clinical assessment of pain in axSpA, the aim of this cross-sectional study was to explore the value of a more detailed pain area assessment as an adjunct to axial and peripheral articular pain intensity and stiffness. More specifically, the aims of this study were as follows:

1. To evaluate the prevalence of pain in anatomically distinct body regions and the body locations within these regions (topographical pain analysis)

2. To determine the association between the extent of axial, peripheral articular and peripheral non-articular pain areas and clinical variables (activity limitations, spinal mobility, disease activity, anxiety and depression)

3. To explore the role of assessing axial, peripheral articular and peripheral non-articular pain areas in the evaluation of the disease activity (using factor analysis)

4. To evaluate gender differences in all analyses.

\section{Methods}

\section{Participants}

Subjects $(n=190)$ with a definite diagnosis of axSpA according to the ASAS classification criteria [19], verified by an ASAS expert rheumatologist (KDV), were randomly included in this cross-sectional observational study. All patients were recruited from the outpatient spondyloarthritis clinic at the University Hospitals of Leuven, Belgium. Subjects with other inflammatory or systemic rheumatic conditions or who were unable to autonomously complete questionnaires in Dutch were excluded.

\section{Outcome measures}

\section{Anthropometrics and demographics}

Height was measured with a stadiometer (Holtain Ltd., Dyfed, UK) to the nearest $0.1 \mathrm{~cm}$, and weight was measured with a digital scale (SECA, Birmingham, UK) to the nearest $0.1 \mathrm{~kg}$. Age (in yr), gender $($ male $=1 /$ female $=2)$, disease duration (in yr), work status (yes $=1 /$ no $=0$ ) and the use of medication (biologicals, NSAIDs, DMARDs, 
analgesics, psychopharmacologics, corticoids, yes $=1 /$ no $=2$ ) were assessed during an interview and verified via the patient's medical record.

\section{Activity limitations}

The ten-item BASFI numerical rating scale was used to assess patient-reported activity limitations [20]. The BASFI is an ASAS-endorsed instrument used to measure activity limitations with well-established psychometric properties in axSpA [2].

\section{Spinal mobility}

The BASMI was used to measure spinal mobility via five clinical tests, namely cervical rotation measured with a goniometer (accuracy 2 degrees; ORTEC Orthopedics, Leuven, Belgium) and a tape measure (accuracy $1 \mathrm{~mm}$; Prym, Stolberg, Germany) of lumbar flexion, lumbar side flexion, tragus-to-wall distance and intermalleolar distance. For cervical rotation, lumbar side flexion and tragus-to-wall distance, the mean of the left and right measurements was taken, and all scores were converted according to the BASMI 10 scoring system [2]. The psychometric properties of the ASAS-endorsed BASMI in axSpA are well established [2, 21, 22].

\section{Disease activity}

The six-item BASDAI numerical rating scale was used to evaluate patient-reported disease activity. As recommended by ASAS, items 5 and 6 combined represented patient-reported inflammation [2]. The one-item Physician Global Assessment of Disease Activity (PGDA) numerical rating scale assessed during the routine rheumatology visit at inclusion represented physician-reported disease activity [2]. C-reactive protein (CRP, in $\mathrm{mg} / \mathrm{L}$ ) served as the laboratory-based disease activity marker [2]. The psychometric properties of the BASDAI, BASDAI inflammation, PGDA and CRP in axSpA are well established [2].

\section{Fear of movement and (re)injury beliefs}

The Tampa Scale for Kinesiophobia Dutch version with 11 items (TSK-11) was used to assess fearful beliefs regarding movement and (re)injury. Each item is provided with a 4-point Likert scale with scoring alternatives ranging from 'strongly disagree' to 'strongly agree' (range, 11-44). The psychometric properties of TSK-11 are well established in chronic pain populations [23] and recently in axSpA [24].

\section{Anxiety and depression}

The 14-item Hospital Anxiety and Depression Scale (HADS) was used to derive information on depression (7 items) and anxiety (7 items) using a 4-point Likert scale with higher values representing more depressed or anxious mood (range, 0-21 for each subscale). The psychometric properties of HADS are well established in axSpA [25].

\section{Pain area}

An anterior and posterior body chart filled in by the patient during the intake interview determined the presence of pain (yes $=1 / \mathrm{no}=0$ ) during the past week in 80 body locations (LOC) from which 22 body regions were derived post hoc (Fig. 1). Articular peripheral body locations were modified from the 76/74-joint count in psoriatic arthritis [26]. Non-articular peripheral body locations were taken from the widespread pain index as applied in the preliminary diagnostic criteria for fibromyalgia [27]. Axial body locations and regions were defined according to the International Association for the Study of Pain [28] and known axial pain referral patterns [29]. A detailed numeric description of pain locations within different body regions is given in Table 2. Widespread axial pain was defined as pain present in the

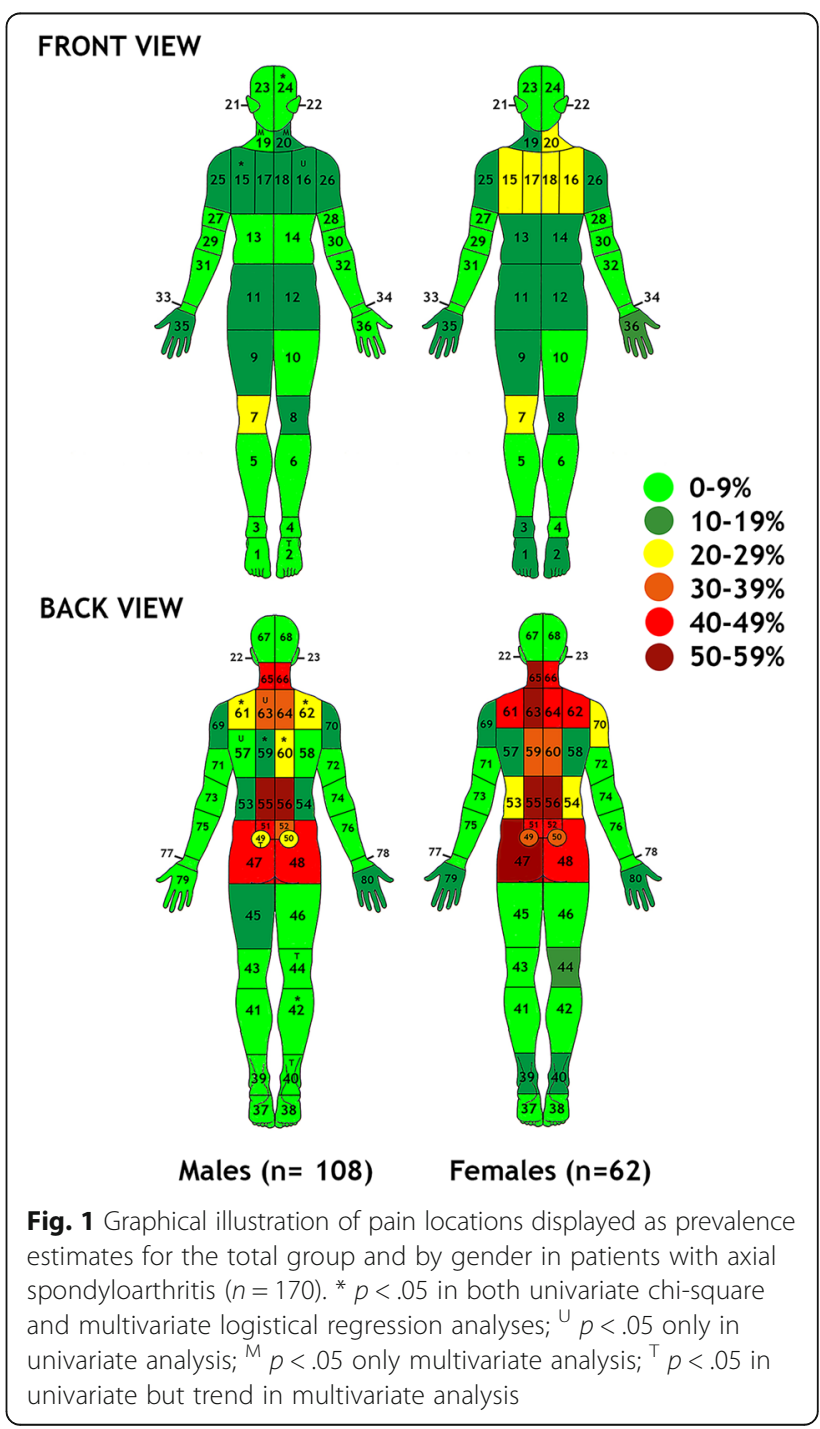


lumbar (LX), thoracic (TX), cervicothoracic junction (CTJ) and cervical (CX) body regions. Widespread peripheral articular (WAP) and non-articular (WNAP) pain was considered present if the sum of painful (non-)articular peripheral body locations exceeded the median for this variable. Axial, peripheral articular and non-articular pain were also calculated as the sum of their respective body locations and expressed as percentages. Two blinded raters with a bachelor's-level degree in physical therapy independently scored the body charts showing good to excellent reliability of this procedure (kappa range, 0.742-1.00; percentage of agreement range, 94-100\%) (Additional file 1: Table S1).

\section{Data reduction and statistical analysis}

Sample characteristics were presented as mean \pm SD and median with IQR or frequencies as percentage. Normal distribution of all variables was evaluated with the Shapiro-Wilk test $(p<.05)$. For each body region and location, prevalence with the corresponding 95\% CI was calculated in the total group and for men and women separately. Cohen's kappa values and percentage of agreement were calculated as inter-rater reliability coefficients $(n=170)$, and thresholds for further use of body charts were set at minimally good $(0.61-0.80)$, preferably excellent $(>0.80)$ [30].

Pain area between genders was univariate compared with an independent $t$ test for continuous variables or chi-square test for frequencies $(p<.05)$. In case of low cell counts (fewer than five) for the latter, the chi-square test was replaced by the phi coefficient to obtain valid $p$ values. For each body region and location as dependent variables, BASDAI inflammation, gender, BASMI, disease duration, age and PGDA were entered as independent variables in a multivariate logistic regression model with ORs and their 95\% CIs as output for the gender comparison. The same independent variables were entered into a multiple linear regression model for axial, articular and non-articular pain sum scores with (un)standardized beta (b, st $\beta$ ) values and their $95 \%$ CIs reported for gender effects.

Pearson product-moment correlation coefficients determined the univariate association between axial, peripheral non-articular and articular pain versus clinical variables $(p<.05)$. Further, clinically relevant subgroups based on the median split of physician-reported disease activity and peripheral non-articular pain (PGDA-/WNAP-, PGDA -/WNAP+, PGDA+/WNAP-, PGDA+/WNAP+) were compared in a multivariate general linear model with subgroup and gender as between-subject factors; BASMI, BMI, disease duration and age as covariates; and BASDAI, BASFI, BASMI, HADS depression and HADS anxiety separately as dependent variables $(p<.05)$. Results of post hoc tests were presented with uncorrected $(p<.05)$ and Bonferroni-corrected $p$ values.
PCA was performed to explore the contribution of all six items of BASDAI and axial, peripheral non-articular and articular pain sum scores in assessing disease activity. The covariance structure was analysed, and variables with an eigenvalue $\geq 1$ were retained. Also, the scree plot was visually inspected to confirm the number of extracted factors. Factor loadings were varimax-rotated, and the variance explained per factor was reported. The magnitude of the rescaled rotated factor loadings determined factor membership for each variable and a large $>0.60$ or smaller $<0.60$ contribution to the total variance explained (Fig. 3). On the basis of this membership, the factor axial disease activity and peripheral disease activity were calculated as the arrhythmic mean of all items within the developed factor without weighting. PCA was repeated per gender to explore structural variability in disease activity outcomes. All analyses were performed with IBM SPSS Statistics version 20.0 software (IBM, Armonk, NY, USA).

\section{Results}

\section{Demographic and anthropometrical data}

Of all 190 patients invited, only 4 refused to participate, resulting in 186 included patients. The numbers of cases with missing data were $2(1.1 \%)$ for the BASMI, 3 (1.6\%) for the TSK-11, 3 (1.6\%) for the HADS, 7 (3.8\%) for the BASFI, 6 (3.2\%) for the BASDAI, 26 for PGDA (14.0\%), 31 for CRP (16.7\%) and 9 for work status (4.8\%). Full data across outcome measures were available for $170 \mathrm{pa}-$ tients (9.1\% data loss) for analyses without PGDA and CRP. Analyses considering PGDA and CRP included 133 subjects (28.4\% data loss). No statistically significant differences were found between groups with or without missing data $(p>.05)$. Descriptive statistics for the total sample and per gender are given in Table 1.

\section{Prevalence and gender differences for pain regions}

Full prevalence data for all pain regions for the total group and per gender are presented in Table 2. Left (10.0\% [9.7$10.3 \%])$ and right (11.2\% [10.8-11.6\%]) whole-leg pain was a rare finding in this axSpA group for both men and women. In contrast, pain in the lumbar spine (LX) was highly prevalent (total group, 74.4\% [74.2-75.2\%]) and significantly more prevalent in women $(83.9 \%$ [83.5-84.3\%]) than in men $(69.4 \%$ [68.9-69.9\%]) in univariate analysis only (chi-square test, 4.338, $p=.037$; OR, 1.74 [0.73-4.14], $p=.210$ ). Pain in the thoracic spine (TX) was remarkably less prevalent overall (32.4\% [31.9-32.9\%]) and in men (25\% [24.5-25.5\%]), but about three times more likely in women (45.2\% [44.6-45.8\%], chi-square test, 7.315, $p=.007$; OR, 2.92 [1.30-6.55], $p=.009$ ). Cervicothoracic junction (CTJ) pain was moderately prevalent overall (47.6\% [47-48.2\%]) and in men (48.1\% [47.5-48.7\%]), but 
Table 1 Descriptive statistics for all demographic, anthropometric and disease-related outcomes in patients with axial spondyloarthritis $(n=170)$

\begin{tabular}{|c|c|c|c|c|c|c|c|}
\hline \multirow[t]{2}{*}{ Variables } & \multicolumn{2}{|c|}{ Total group $(n=170)$} & \multicolumn{2}{|c|}{ Men $(n=108)$} & \multicolumn{2}{|c|}{ Women $(n=62)$} & \multirow[b]{2}{*}{$p$ Value } \\
\hline & Mean (SD) & Med (IQR) & Mean (SD) & Med (IQR) & Mean (SD) & Med (IQR) & \\
\hline Age, yr & $42.9(12.2)$ & $42.7(20.3)$ & $43.8(12.5)$ & $43.2(20.4)$ & $41.3(11.5)$ & $42.1(18.0)$ & .199 \\
\hline Disease duration, yr & $13.1(11.1)$ & $10.7(16.6)$ & $14.0(11.2)$ & $11.9(18.4)$ & $11.5(11.0)$ & $8.8(13.0)$ & .155 \\
\hline Height, cm & $171.6(9.4)$ & $172.3(12.9)$ & $176.2(7.1)$ & $176.2(9.1)$ & $163.7(7.4)$ & $163.4(9.5)$ & $<.00$ \\
\hline Weight, kg & $77.0(15.0)$ & $76.6(20.9)$ & $81.7(13.9)$ & $80.5(19.2)$ & $69.7(13.4)$ & $67.0(18.1)$ & $<.00$ \\
\hline $\mathrm{BMI}, \mathrm{kg} / \mathrm{m}^{2}$ & $26.1(4.4)$ & $25.6(6.4)$ & $26.3(4.4)$ & $25.5(6.1)$ & $25.7(4.4)$ & $25.7(7.1)$ & .408 \\
\hline BASDAI (0-10) & $3.8(2.1)$ & $3.7(3.3)$ & $3.6(2.2)$ & $3.5(3.5)$ & $4.3(2.0)$ & $4.2(3.1)$ & .027 \\
\hline PGDA $(0-10)(n=146)$ & $1.4(1.8)$ & $1.0(2.0)$ & $1.4(1.9)$ & $0.9(2.0)$ & $1.4(1.6)$ & $1.0(1.6)$ & .583 \\
\hline CRP, mg/L $(n=141)$ & $8.3(16.0)$ & $2.9(6.6)$ & $8.9(16.5)$ & $3.0(6.6)$ & $7.4(15.3)$ & $2.2(6.7)$ & .810 \\
\hline BASFI (0-10) & $3.6(2.4)$ & $3.4(3.8)$ & $3.5(2.4)$ & $3.2(4.0)$ & $3.8(2.3)$ & $3.7(3.7)$ & .459 \\
\hline BASMI (0-10) & $3.0(1.8)$ & $2.8(2.0)$ & $3.3(2.0)$ & $2.8(2.8)$ & $2.6(1.2)$ & $2.6(1.6)$ & .002 \\
\hline Cervical rotation, degrees & $60.5(19.6)$ & $65.0(25.0)$ & $58.0(21.3)$ & $62.5(27.8)$ & $65.0(15.6)$ & $66.0(20.5)$ & .015 \\
\hline Tragus to wall, $\mathrm{cm}$ & $13.6(4.6)$ & $11.7(4.5)$ & $14.9(5.0)$ & $13.3(6.2)$ & $11.4(2.3)$ & $10.8(1.8)$ & $<.00$ \\
\hline Lateral flexion, cm & $12.4(5.1)$ & $12.7(8.1)$ & $11.7(6.1)$ & $12.1(9.4)$ & $13.5(4.2)$ & $13.1(6.1)$ & .028 \\
\hline Intermalleolar distance, $\mathrm{cm}$ & $99.0(22.6)$ & $103.3(25.1)$ & $101.0(21.4)$ & $105.2(25.2)$ & $95.5(24.2)$ & $100.7(25.0)$ & .141 \\
\hline Modified Schober, cm & $5.3(2.1)$ & $5.5(2.5)$ & $4.9(2.3)$ & $5.2(3.1)$ & $5.9(1.7)$ & $6.2(2.0)$ & .002 \\
\hline TSK-11 (11-44) & $24.8(6.3)$ & $25.0(10.0)$ & $27.8(6.4)$ & $25.0(10.0)$ & $24.9(6.0)$ & $25.0(9.3)$ & .888 \\
\hline HADS depression (0-21) & $4.6(3.6)$ & $4.0(5.0)$ & $4.8(3.7)$ & $4.0(5.0)$ & $4.4(3.5)$ & $3.0(4.0)$ & .580 \\
\hline HADS anxiety (0-21) & $7.1(3.6)$ & $7.0(5.0)$ & $6.7(3.4)$ & $7.0(5.0)$ & $7.8(3.9)$ & $7.5(5.0)$ & .071 \\
\hline \multicolumn{8}{|l|}{ Frequencies (\%) } \\
\hline Gender, male/female & \multicolumn{2}{|c|}{$108 / 62(64 / 36)$} & \multicolumn{2}{|l|}{ NA } & \multicolumn{2}{|l|}{ NA } & NA \\
\hline NSAIDs, yes/no & \multicolumn{2}{|c|}{$87 / 83(51 / 49)$} & \multicolumn{2}{|l|}{$56 / 52(52 / 48)$} & \multicolumn{2}{|l|}{$31 / 31(50 / 50)$} & .816 \\
\hline Biologicals, yes/no & \multicolumn{2}{|c|}{ 67/103 (39/61) } & \multicolumn{2}{|l|}{$45 / 63(42 / 58)$} & \multicolumn{2}{|l|}{$22 / 40(36 / 64)$} & .427 \\
\hline Corticosteroids, yes/no & \multicolumn{2}{|c|}{$12 / 158(7 / 93)$} & \multicolumn{2}{|l|}{ 6/102 (6/94) } & \multicolumn{2}{|l|}{$6 / 56(10 / 90)$} & $.313^{\mathrm{a}}$ \\
\hline DMARDs, yes/no & \multicolumn{2}{|c|}{$71 / 99(42 / 58)$} & \multicolumn{2}{|l|}{$43 / 65(40 / 60)$} & \multicolumn{2}{|l|}{$28 / 34(45 / 55)$} & .496 \\
\hline Psychopharmacologic agents, yes/no & \multicolumn{2}{|c|}{$12 / 158(7 / 93)$} & \multicolumn{2}{|l|}{ 6/102 (6/94) } & \multicolumn{2}{|l|}{$6 / 56(10 / 90)$} & $.313^{a}$ \\
\hline Analgesics, yes/no & \multicolumn{2}{|c|}{$73 / 97(43 / 57)$} & \multicolumn{2}{|l|}{$33 / 75(31 / 69)$} & \multicolumn{2}{|l|}{$40 / 22(65 / 35)$} & $<.00$ \\
\hline Work status, yes/no ${ }^{b}$ & \multicolumn{2}{|c|}{$99 / 64(61 / 39)$} & \multicolumn{2}{|l|}{$64 / 38(63 / 37)$} & \multicolumn{2}{|l|}{$35 / 26(57 / 43)$} & .497 \\
\hline
\end{tabular}

Abbreviations: BMI Body mass index, BASDAI Bath Ankylosing Spondylitis Disease Activity Index, BASFI Bath Ankylosing Spondylitis Functional Index, BASMI Bath Ankylosing Spondylitis Metrology Index, CRP C-reactive protein, normal value $<5 \mathrm{mg} / \mathrm{L}$, HADS Hospital Anxiety and Depression Scale, NSAIDs Non-steroidal antiinflammatory drugs, DMARDs Disease-modifying anti-rheumatic drugs, $p<.05$

${ }^{a} p$ Value based on phi coefficient instead of chi Square test

${ }^{\mathrm{b}} n=163$ (9 males, 2 females missing)

about two and one-half times more likely in women (66.1\% [65.6-66.6\%], chi-square test, 5.139, $p=.023$; OR, 2.48 [1.17-5.26], $p=.018)$. Pain in the cervical spine and head (CX and head) was also common overall $(47.6 \%$ [47-48.2\%]), but not significantly different between men (45.4\% [44.8-46.0\%]) and women (51.6\% [51-52.2\%]) $(p>.05)$. Isolated occurrence of lumbar (LX only, $21.2 \%$ [20.7-21.7\%]) and cervical (CX only, 10.6\% [10.2-11.0\%]) spine pain was common, but not in the thoracic spine (TX only, 2.4 [2.2-2.6\%]). Also, no apparent gender differences existed $(p>.05)$. Widespread axial pain was moderately prevalent $(26.5 \%[26.0-27.0 \%])$ and about three times more likely in women $(38.7 \%$ [38.1-39.3\%]) than in men (19.4\% [18.9-19.9\%]) (chi-square test, 7.511, $p=.006$; OR, 3.33 [1.38-8.02], $p=.007)$. Widespread articular peripheral pain also showed a twofold increased likelihood in women $(56.5 \%$ [55.9-57.1\%]) compared with men (40.7\% [40.1-41.3\%]; chi-square test, 3.908, $p=.048$; OR, 2.34 [1.12-4.88], $p=.023)$, whereas for widespread non-articular peripheral pain, statistical significance was not met $(p=.079)$. The sum score for axial pain locations (total group mean $\pm \mathrm{SD}, 36.1 \pm 21.1$; median [IQR], 27.3 [28.4]) was significantly higher in women (mean $\pm \mathrm{SD}$, $37.5 \pm 20.8$; median [IQR], 36.4 [36.4]) than in men (mean \pm SD, $28.3 \pm 20.7$; median [IQR], 27.3 [31.9]; t-test $p=.006 ; \mathrm{b}=8.52[1.42-15.63] ; \mathrm{st} ß=.193 ; p=.019)$. No 
Table 2 Prevalence estimates and gender differences in painful body regions in patients with axial spondyloarthritis $(n=170)$

\begin{tabular}{|c|c|c|c|c|c|c|c|c|}
\hline Body region & Location numbers & Total group & $\begin{array}{l}\text { Males } \\
(n=108)\end{array}$ & $\begin{array}{l}\text { Females } \\
(n=62)\end{array}$ & $\begin{array}{l}\text { Chi-square } \\
\text { value }\end{array}$ & $p$ Value & $O R^{a}$ & $p$ Value \\
\hline Leg right & $41,43,45,47$ & $11.2(10.8-11.6)$ & $10.2(9.9-10.5)$ & $12.9(12.5-13.3)$ & 0.293 & .588 & $1.35(0.43-4.30)$ & .588 \\
\hline Leg left & $42,44,46,48$ & $10(9.7-10.3)$ & $9.3(9-9.6)$ & $11.3(10.9-11.7)$ & 0.181 & .671 & $0.77(0.21-2.77)$ & .687 \\
\hline SIJ & 49,50 & $32.9(32.4-33.4)$ & $26.9(26.4-27.4)$ & $43.5(42.9-44.1)$ & 4.971 & .026 & $1.76(0.82-3.81)$ & .149 \\
\hline$L X$ & $47-56$ & $74.7(74.2-75.2)$ & $69.4(68.9-69.9)$ & $83.9(83.5-84.3)$ & 4.338 & .037 & $1.74(0.73-4.14)$ & .210 \\
\hline TX & $57-60$ & $32.4(31.9-32.9)$ & $25(24.5-25.5)$ & $45.2(44.6-45.8)$ & 7.315 & .007 & $2.92(1.30-6.55)$ & .009 \\
\hline CTJ & $61-64$ & $47.6(47-48.2)$ & $48.1(47.5-48.7)$ & $66.1(65.6-66.6)$ & 5.139 & .023 & $2.48(1.17-5.26)$ & .018 \\
\hline$C X$ & 65,66 & $47.6(47-48.2)$ & $45.4(44.8-46.0)$ & $51.6(51-52.2)$ & 0.615 & .433 & $1.55(0.75-3.23)$ & .240 \\
\hline CX and head & $19-24,65-68$ & $54.7(54.1-55.3)$ & $50.9(50.3-51.5)$ & $61.3(60.7-61.9)$ & 1.708 & .191 & $1.71(0.81-3.60)$ & .159 \\
\hline Sternum & 17,18 & $20.6(20.1-21.1)$ & $18.5(18.1-18.9)$ & $24.2(23.7-24.7)$ & 0.776 & .378 & $0.98(0.39-2.48)$ & .972 \\
\hline LX only & $47-56$ & $21.2(20.7-21.7)$ & $20.4(19.9-20.9)$ & $22.6(22.1-23.1)$ & 0.115 & .734 & $0.97(0.41-2.30)$ & .944 \\
\hline TX only & $57-60$ & $0.6(1.5-0.7)$ & $0.0(0.0-0.0)$ & $1.6(1.5-1.7)$ & $0.102^{\mathrm{b}}$ & .186 & $0.00(0.00-0.00)$ & .999 \\
\hline CX only & $61-68$ & $10.6(10.2-11.0)$ & $12.0(11.5-12.4)$ & $8.1(7.8-8.4)$ & 0.657 & .418 & $1.02(0.31-3.34)$ & .999 \\
\hline Widespread axial pain & $47-66^{c}$ & $26.5(26.0-27.0)$ & $19.4(18.9-19.9)$ & $38.7(38.1-39.3)$ & 7.511 & .006 & $3.33(1.38-8.02)$ & .007 \\
\hline $\begin{array}{l}\text { Widespread peripheral } \\
\text { articular pain }\end{array}$ & $\begin{array}{l}1-4,7,8,25,26 \\
29,30,33-36 \\
37-40,43,44,73 \\
74,77-80\end{array}$ & $46.5(45.9-47.1)$ & $40.7(40.1-41.3)$ & $56.5(55.9-57.1)$ & 3.908 & .048 & $2.34(1.12-4.88)$ & .023 \\
\hline $\begin{array}{l}\text { Widespread peripheral } \\
\text { non-articular pain }\end{array}$ & $\begin{array}{l}5,6,9-14,25-28 \\
31,32,41,42,45 \\
46,69-72,75,76\end{array}$ & $44.7(44.1-45.3)$ & $39.8(39.2-40.4)$ & $53.2(52.6-53.8)$ & 2.866 & .090 & $1.97(0.93-4.15)$ & .079 \\
\hline
\end{tabular}

Abbreviations: SIJ Sacroiliac joint, LX Lumbar spine, CX Cervical spine, TX Thoracic spine, CTJ Cervicothoracic junction

${ }^{a}$ Multivariate $\mathrm{OR} \pm 95 \% \mathrm{Cl}$ based on logistic regression analysis correcting for age, disease duration, spinal mobility (Bath Ankylosing Spondylitis Metrology Index), disease activity (Bath Ankylosing Spondylitis Disease Activity Index and physician global assessment of disease activity $(n=146)$

${ }^{b} \mathrm{Phi}$ value is given because of low cell frequency (fewer than cases); significant results in bold; $p<.05$

c Positive if pain is present in regions 47-56 and 57-60 and in regions 61-64 and 65-66

gender differences were found for articular (total group mean $\pm \mathrm{SD}, 9.2 \pm 12.3$; median [IQR], 3.8 [15.4]) and non-articular (total group mean $\pm \mathrm{SD}, 7.6 \pm 10.0$; median [IQR], 4.2 [12.5]) peripheral pain sum scores $(p>.05)$.

\section{Within-region prevalence and gender differences in pain locations}

Full prevalence data for all 80 pain locations for the total group and per gender are presented in Additional file 2: Table S2 and graphically summarized in Fig. 1. Overall, the dominant axial involvement in axSpA was clearly confirmed for both genders. Of note was a higher prevalence of pain in the anterior right knee ( $\mathrm{LOC} 7,21.8 \%$ [21.3-22.3\%]), regardless of gender. In addition to the predominance of regional CX and CTJ pain in women, the within-region results also confirmed the increased lateral spread of pain in the CTJ region in women (LOC 61, 45.2\% [44.6-45.8\%]; LOC 62, 41.9\% [41.3-42.5\%]) compared with men (LOC 61, 26.9\% [26.4-27.4\%]; chi-square test, 5.925, $p=.015$; OR, 2.23 [1.05-4.71], $p=.036$; LOC 62, 24.1\% [23.6-24.6\%]; chi-square test, $5.918, p=.015 ;$ OR, $2.48[1.14-5.42], p=.023)$. A similar effect did not reach significance in the thoracic or lumbar region $(p>.05)$.
Relationship of pain regions with disease-related outcomes Univariate correlations between all variables for the total group and per gender can be found in Additional file 3: Table S3. General linear models (Fig. 2, Additional file 4: Table S4) revealed a graded relationship between subgroups combining non-articular peripheral pain and PGDA with BASFI, BASDAI, TSK-11 and HADS in men $(p<.05)$. Of clinical interest was the subgroup of non-articular peripheral pain combined with low PGDA (WNAP+/PGDA-; 27\% of all patients) that was associated with worse BASFI, BASDAI, and HADS anxiety and depression in men and worse TSK-11 and HADS anxiety in women $(p<.05)$.

\section{Role of pain area in disease activity}

Factor analysis revealed a differential role for body regions in the assessment of disease activity (Fig. 3). Axial pain sum score loaded on an axial disease factor together with BASDAI items 1,2 and 6 to explain $11 \%$ of the variance. Non-articular and articular peripheral pain sum score loaded on a peripheral disease activity factor explained $56 \%$ of the variance. Importantly, the factor structure did vary between genders with a single- and two-factor solution in men and women, respectively. 


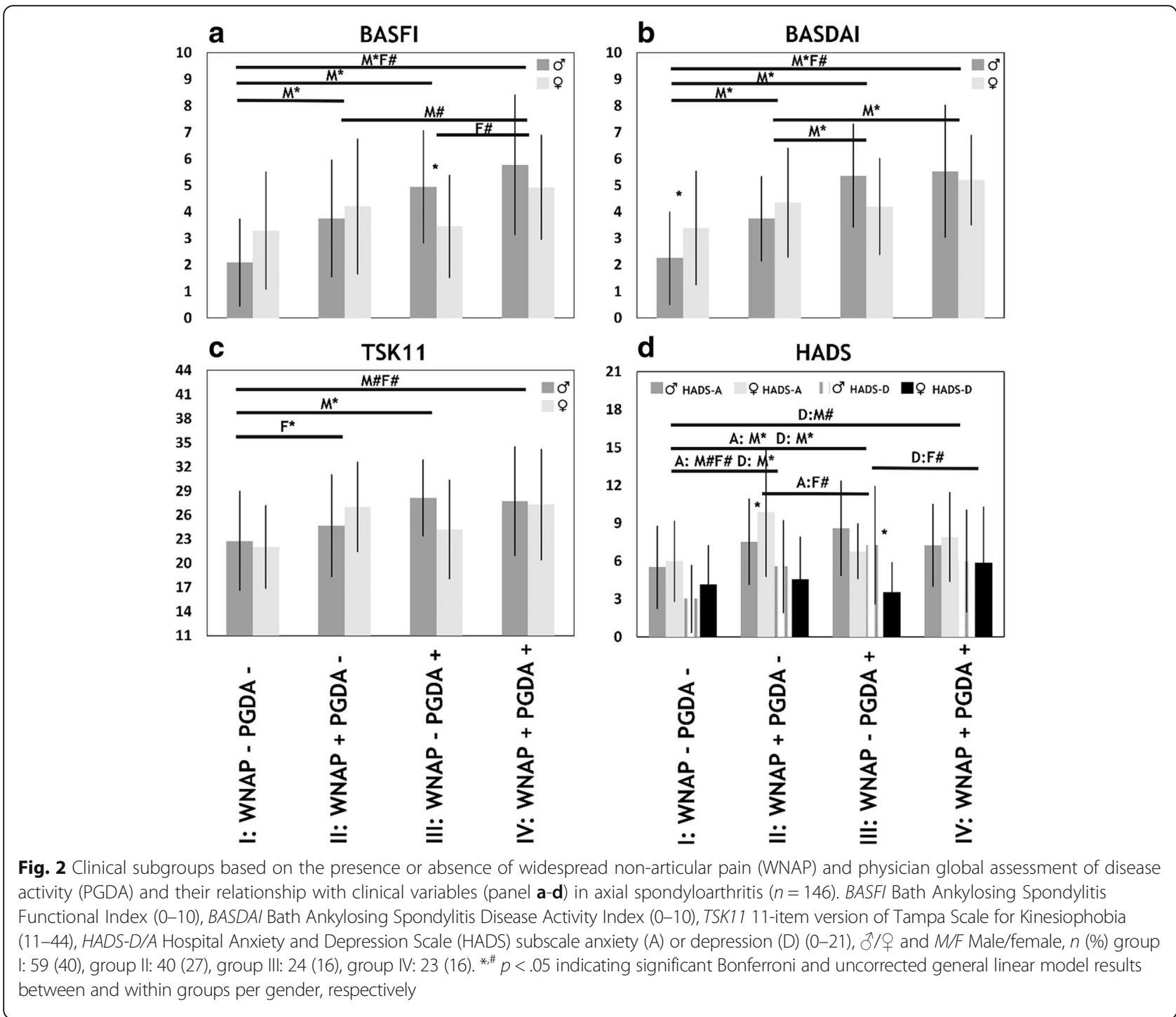

\section{Discussion}

To the best of our knowledge, this was the first study to detail the topography of pain in axSpA and to relate these findings to key clinical outcomes and the structural properties of BASDAI, the most commonly used self-reported method to assess disease activity. In the first part of the study, the prevalence of pain in clinically meaningful body regions was analysed. The observed dominant axial pain involvement likely confirmed axial disease, as enforced by the ASAS axSpA inclusion criteria [19]. The prevalence of pain was highest in the LX region (75\%) when compared with the TX (34\%), CTJ (48\%) and CX (48\%) regions. Indeed, the LX region was reported to be the first (LX: $67 \%$, buttock: $40 \%$, TX: 23.3\%, CX/CTJ: $11.1 \%$ ) and dominant (LX, 90\%; buttock, $75 \%$; TX, 55\%) area affected in a large recent-onset inflammatory back pain cohort [31]. Comparable descriptions of axial pain locations in historic axSpA cohorts do not exist [32]; however, preferential thoracic inflammation and bone formation (thus discrepant with our dominant LX pain symptoms) have been reported [33]. We also found a strikingly low prevalence of unique pain involvement of the LX (20\%), TX (1\%) and CX (10\%) regions. Blachier et al. [34] recently reported a similarly low TX (2\%) but contrasting low LX (2\%) with high SIJ (25\%) prevalence of single inflammatory lesions visualised by magnetic resonance imaging (MRI). The mismatch at the lumbar level in our study can be explained by referral of pain in the LX region owing to SIJ inflammation [29, 35] or common local LX pain with a non-inflammatory origin, a differentiation that needs further study. For the peripheral joints, the more pronounced involvement of the right anterior knee may reflect increased loading of the dominant limb [36] and fits with the proposed link between biomechanics and disease processes in axSpA [37]. 


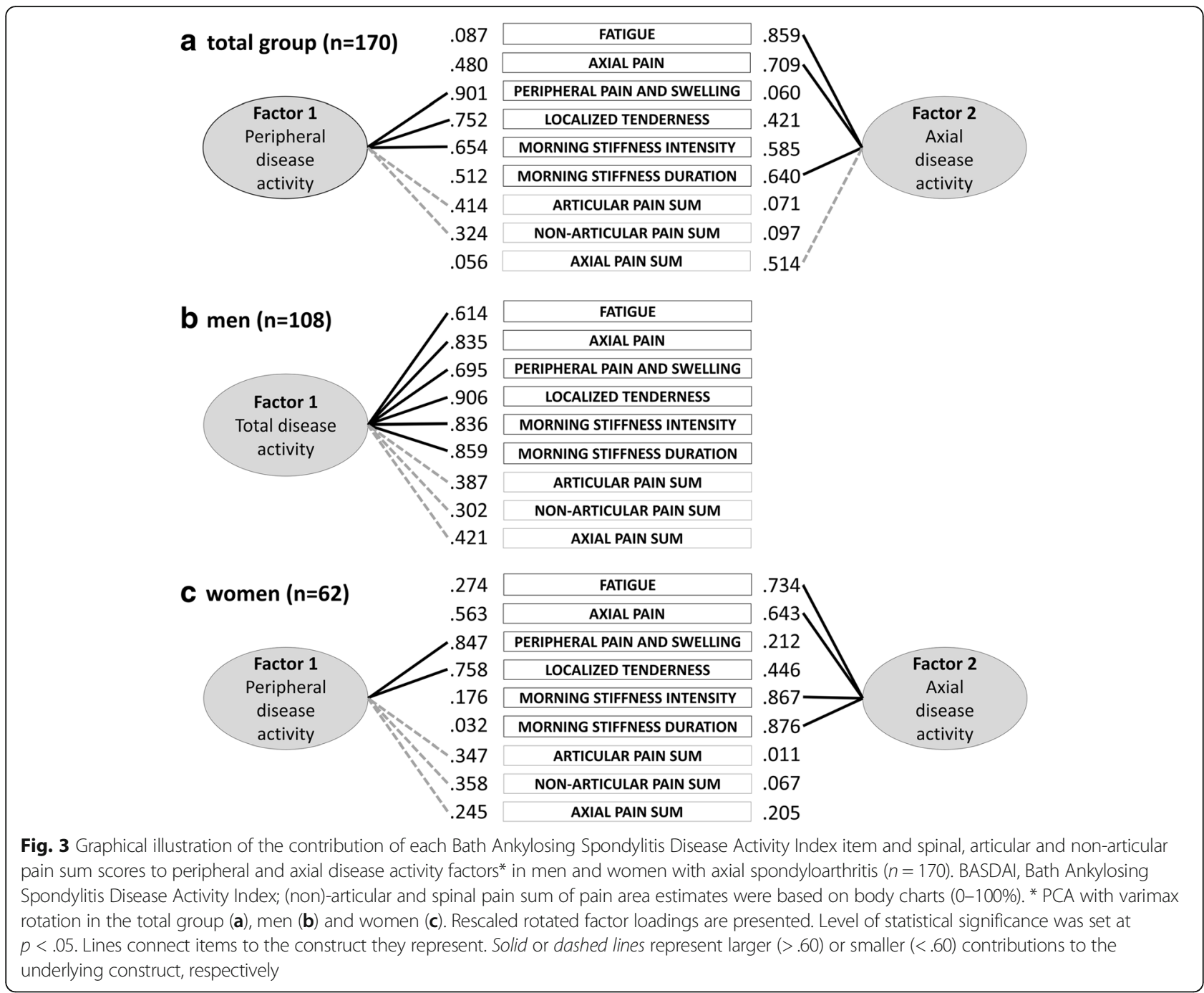

In the second part of the study, gender comparisons in regional pain prevalence revealed increased pain in the TX and CTJ, but not the CX region, in women. In the absence of other research on this topic, the observed gender differences in thoracic pain represent a novel finding. In contrast, the results of our study for the CTJ region probably coincided with the marked but ill-defined CX involvement in women that has been reported previously in both radiographic [32] and early axSpA cohorts [38]. Interestingly, and unique to this study, further within-region analysis revealed that the lateral spread of CTJ and sternal pain is more prevalent in women. On the basis of previous work on anterior chest pain, researchers have reported rather similar sternal pain occurrence between men and women, but focused on local joint pain only $[39,40]$.

In the third part of the study, on the widespread nature of pain and its clinical correlates, this cohort showed a fairly high occurrence of widespread spinal pain (27\%) and spinal pain sum scores (35\%), regardless of disease status and being even more pronounced in women (39\% and 38\%, respectively). Although rooted in different criteria definitions, these numbers mimic the prevalence of fibromyalgia in women with axSpA $(39 \%$ versus range $11-34 \%$ ) typically reported in the literature, but they were higher than expected in men (19\% versus range $2-9 \%)[12,15,16,27]$. The latter may indicate incomplete correction for pain caused by partial bone formation via BASMI, a process known to affect the spine more in men [17]. These findings need careful interpretation, however, because multiple mechanisms may lead to a wider spread of spinal pain. Commonly involved anterior (e.g., anterior vertebral corner) versus posterior (e.g., zygapophyseal joint) spinal structures in axSpA have been shown to exhibit multisegmental/bilateral to unisegmental/unilateral innervation, respectively [41]. Consequently, the amount of disease processes, as well as the innervation pattern of the specific local tissues 
involved, likely results in a variable pain extent via local mechanisms of nociceptor activation and peripheral sensitization (primary hyperalgesia) [29, 35]. Also, central neural plasticity likely augments pain area and intensity in axSpA, especially in women [42], owing to activity- and transcription-dependent long-term potentiation (mono- and heterosynaptic) recruiting nearby receptive fields, a changed neural membrane excitability, the disinhibition of anti-nociceptive and facilitation of pro-nociceptive top-down pathways, all strongly influenced by immune-competent cells such as microglia (secondary hyperalgesia and widespread pain) [13].

To date, researchers in the few preliminary studies on pain physiology in axSpA have reported normal [43] (also in response to anti-TNF treatment [44]) to even elevated [45] pain pressure thresholds compared with control subjects and a moderate relationship with depression [46], non-superiority of algometry over manual palpation in the evaluation of entheseal pain [47] and pain-related brain morphology changes in response to anti-TNF treatment [11, 44], but all studies lacked proper gender comparisons. (For a recent mechanistic overview of gender differences in clinical and experimental non-axSpA pain research, see [42].) The observed increased widespread articular pain and trend for non-articular pain in women have been reported inconsistently in the literature $[17,32]$ and require a conclusive differentiation of local disease versus pain mechanisms. Further characterisation of the subgroup 'low disease activity but high spread of pain' (PGDA -/WPIP+) in this study, exhibiting a large burden of disease and association with anxiety in both genders and with depression in males, may help in this respect. Future work should concurrently include state-ofthe-art assessment of inflammation/bone formation, pain mechanisms (including fibromyalgia criteria), psychosocial variables and clinical outcomes to unravel the spread of pain by gender, especially in clinically relevant subgroups of axSpA.

In the last part of the study, we revealed a two-factor structure of BASDAI that was linked to female gender and suggests the importance of considering axial and peripheral disease activity separately in women. Only one study reported a one-factor structure of BASDAI in both ankylosing spondylitis ( $n=211,82 \%$ men) and early spondyloarthritis $(n=86,56 \%$ men), results that likely diverge from those of our study owing to lesser representation of women and small sample size [48]. Screening existing disease activity instruments in axSpA for gender compatibility is urgently needed. The impact of gender on cut-offs to define disease activity using the recently developed ASDAS in women has been reported [49] and may add to explanation of the lower response to biological therapy in women [50].
This study has a few limitations. First, we corrected all pain area estimates for differences in clinical outcome but were not able to include the ASDAS (missing patient global assessment) or MRI (feasibility and cost) to study local inflammation. In the absence of a gold standard [2], it is a strength, however, that objective and valid surrogate measures PGDA and CRP were included [51]. Similarly, plain radiographs were not available to evaluate bone formation, which was reflected by the reliable and valid BASMI [21]. Second, although this is the largest study reported to date on detailed topographical pain analysis axSpA, it must be recognized that our subgroup analysis is (for sample size reasons) exploratory. As a consequence, relevant differences between subgroups may have been missed. To tackle this power issue, we presented the uncorrected and corrected $p$ values.

\section{Conclusions}

This study describes the topography of pain in axSpA in detail. Apart from the dominant axial prevalence of pain, especially in the LX region, women more frequently exhibited TX and CTJ pain with a wider lateral spread, regardless of disease status. Our finding of widespread (non-articular) peripheral pain in combination with low PGDA questions current clinical decision-making using disease activity measures in a subgroup of axSpA. Also, the two-factor structure of disease activity found in women should be considered in the development of outcome instruments in axSpA.

\section{Additional files}

Additional file 1: Table S1. Inter-rater reliability for each body chart region for the topographical pain assessment in patients with axial spondyloarthritis $(n=170)$. Reliability data for each body chart location. (XLSX $18 \mathrm{~kb}$ )

Additional file 2: Table S2. Painful body locations expressed as prevalence estimates for the total group and by gender in patients with axial spondyloarthritis $(n=170)$. Detailed analysis of prevalence outcomes per body location and per gender. (XLSX $19 \mathrm{~kb}$ )

Additional file 3: Table S3. Univariate Pearson product-moment correlations between all pain area estimates and clinical outcomes in patients with axial spondyloarthritis $(n=170)$. Correlation table for all pain area estimates and clinical outcomes. (XLSX $19 \mathrm{~kb}$ )

Additional file 4: Table S4. General linear model results comparing clinical outcomes between subgroups based on WNAP and PGDA status across and within genders in patients with axial spondyloarthritis $(n=146)$. Full subgroup comparison data across and within genders. (XLSX $15 \mathrm{~kb})$

\section{Abbreviations}

+/-: Is/is not present; ASAS: Assessment in SpondyloArthritis international Society; ASDAS: Ankylosing Spondylitis Disease Activity Index; axSpA: Axial spondyloarthritis; $\beta$ : Standardized $\beta$-value; b: Unstandardized $\beta$-value; BASDAI: Bath Ankylosing Spondylitis Disease Activity Index; BASFI: Bath Ankylosing Spondylitis Functional Index; BASMI: Bath Ankylosing Spondylitis Metrology Index; CRP: C-reactive protein; CTJ: Cervicothoracic junction body region; CX: Cervical body region; DMARDs: Disease-modifying anti-rheumatic drugs; HADS: Hospital Anxiety and Depression Scale; HLA: Human leucocyte 
antigen; IL: Interleukin; LOC: Body location(s); LX: Lumbar body region; MRI: Magnetic resonance imaging; NSAIDs: Non-steroidal anti-inflammatory drugs; ORs: Odds Ratios; PCA: Principal Component Analysis; PGDA: Physician global assessment of disease activity; SIJ: Sacroiliac joint region; TNF: Tumour necrosis factor; TSK-11: Tampa Scale for Kinesiophobia 11-item version; TX: Thoracic body region; WAP: Widespread peripheral articular; WNAP: Widespread non-articular pain

\section{Acknowledgements}

We thank all participants and staff members of UZ Leuven who operationally contributed to this study. In particular, we thank Evelyne Raddoux and Tim Van Rietvelde for their help in scoring the body charts for reliability purposes.

\section{Funding}

Funding for this study was provided by the Division of Rheumatology, University Hospitals Leuven, and Fonds voor Wetenschappelijk Reuma Onderzoek (FWRO), Brussels.

\section{Availability of data and materials}

The datasets used and/or analysed during the present study are available from the corresponding author on reasonable request.

\section{Authors' contributions}

TWS, RW, WD and KdV were involved in the conception and design of the study; the acquisition, analysis and interpretation of data; and finalizing the manuscript. All authors read and approved the manuscript.

\section{Ethics approval and consent to participate}

Prior to participation, all subjects provided written informed consent according to the Declaration of Helsinki. The study protocol was approved by the Medical Ethics Committee of the University Hospitals Leuven (ML 5236).

\section{Competing interests}

The authors declare that they have no competing interests.

\section{Publisher's Note}

Springer Nature remains neutral with regard to jurisdictional claims in published maps and institutional affiliations.

\section{Author details}

'Division of Rheumatology, University Hospitals Leuven, Herestraat 49, 3000 Leuven, Belgium. ${ }^{2}$ Skeletal Biology and Engineering Research Center, Department of Development and Regeneration, KU Leuven, Herestraat 49 box 7003/13, 3000 Leuven, Belgium. ${ }^{3}$ Musculoskeletal Rehabilitation Research Unit, Department of Rehabilitation Sciences, KU Leuven, Tervuursevest 101 box 1501, 3001 Leuven, Belgium.

Received: 5 February 2018 Accepted: 14 May 2018

Published online: 27 July 2018

\section{References}

1. Pedersen SJ, Poddubnyy D, Sørensen IJ, Loft AG, Hindrup JS, Thamsborg G, et al. Course of magnetic resonance imaging-detected inflammation and structural lesions in the sacroiliac joints of patients in the randomized, doubleblind, placebo-controlled Danish multicenter study of adalimumab in spondyloarthritis, as assessed by the Berlin and Spondyloarthritis Research Consortium of Canada methods. Arthritis Rheumatol. 2016;68(2):418-29.

2. Sieper J, Rudwaleit M, Baraliakos X, Brandt J, Braun J, Burgos-Vargas R, et al. The Assessment of SpondyloArthritis international Society (ASAS) handbook: a guide to assess spondyloarthritis. Ann Rheum Dis. 2009;68(Suppl 2):ii1-44.

3. Maksymowych WP, Crowther SM, Dhillon SS, Conner-Spady B, Lambert RG. Systematic assessment of inflammation by magnetic resonance imaging in the posterior elements of the spine in ankylosing spondylitis. Arthritis Care Res (Hoboken). 2010;62(1):4-10.

4. Jacques $P, M c G o n a g l e ~ D$. The role of mechanical stress in the pathogenesis of spondyloarthritis and how to combat it. Best Pract Res Clin Rheumatol. 2014;28(5):703-10.

5. Tito RY, Cypers H, Joossens M, Varkas G, Van Praet L, Glorieus E, et al. Dialister as a microbial marker of disease activity in spondyloarthritis. Arthritis Rheumatol. 2017;69(1):114-21.
6. Venken K, Elewaut D. New immune cells in spondyloarthritis: key players or innocent bystanders? Best Pract Res Clin Rheumatol. 2015;29(6):706-14.

7. Ambarus C, Yeremenko N, Tak PP, Baeten D. Pathogenesis of spondyloarthritis: autoimmune or autoinflammatory? Curr Opin Rheumatol. 2012;24(4):351-8.

8. Woolf CJ. What is this thing called pain? J Clin Invest. 2010;120(11):3742-4.

9. Hodges PW, Smeets RJ. Interaction between pain, movement, and physical activity: short-term benefits, long-term consequences, and targets for treatment. Clin J Pain. 2015;31(2):97-107.

10. Rudwaleit M, Metter A, Listing J, Sieper J, Braun J. Inflammatory back pain in ankylosing spondylitis: a reassessment of the clinical history for application as classification and diagnostic criteria. Arthritis Rheum. 2006;54(2):569-78.

11. Wu Q, Inman RD, Davis KD. Neuropathic pain in ankylosing spondylitis: a psychophysics and brain imaging study. Arthritis Rheum. 2013;65(6):1494-503.

12. Salaffi F, De Angelis R, Carotti M, Gutierrez M, Sarzi-Puttini P, Atzeni F. Fibromyalgia in patients with axial spondyloarthritis: epidemiological profile and effect on measures of disease activity. Rheumatol Int. 2014;34(8):1103-10.

13. Latremoliere A, Woolf $\mathrm{CJ}$. Central sensitization: a generator of pain hypersensitivity by central neural plasticity. J Pain. 2009;10(9):895-926.

14. Brionez TF, Assassi S, Reveille JD, Green C, Learch T, Diekman L, et al. Psychological correlates of self-reported disease activity in ankylosing spondylitis. J Rheumatol. 2010;37(4):829-34.

15. Almodovar R, Carmona L, Zarco P, Collantes E, Gonzalez C, Mulero J, et al. Fibromyalgia in patients with ankylosing spondylitis: prevalence and utility of the measures of activity, function and radiological damage. Clin Exp Rheumatol. 2010;28(6 Suppl 63):S33-9.

16. Azevedo VF, Paiva Edos S, Felippe LR, Moreira RA. Occurrence of fibromyalgia in patients with ankylosing spondylitis. Rev Bras Reumatol. 2010;50(6):646-50.

17. Webers C, Essers I, Ramiro S, Stolwijk C, Landewé R, van der Heijde D, et al. Gender-attributable differences in outcome of ankylosing spondylitis: longterm results from the Outcome in Ankylosing Spondylitis International Study. Rheumatology (Oxford). 2016;55(3):419-28.

18. Ramiro S, van Tubergen A, Stolwijk C, van der Heijde D, Royston P, Landewé R. Reference intervals of spinal mobility measures in normal individuals: the MOBILITY study. Ann Rheum Dis. 2015;74(6):1218-24.

19. Sieper J, van der Heijde D, Landewé R, Brandt J, Burgos-Vagas R, CollantesEstevez $\mathrm{E}$, et al. New criteria for inflammatory back pain in patients with chronic back pain: a real patient exercise by experts from the Assessment of SpondyloArthritis international Society (ASAS). Ann Rheum Dis. 2009;68(6):784-8.

20. Calin A, Garrett S, Whitelock H, Kennedy LG, O'Hea J, Mallorie P, et al. A new approach to defining functional ability in ankylosing spondylitis: the development of the Bath Ankylosing Spondylitis Functional Index. J Rheumatol. 1994;21(12):2281-5.

21. Castro MP, Stebbings SM, Milosavljevic S, Bussey MD. Construct validity of clinical spinal mobility tests in ankylosing spondylitis: a systematic review and meta-analysis. Clin Rheumatol. 2016;35(7):1777-87.

22. Jenkinson TR, Mallorie PA, Whitelock HC, Kennedy LG, Garrett SL, Calin A. Defining spinal mobility in ankylosing spondylitis (AS): the Bath AS Metrology Index. Index J Rheumatol. 1994;21(9):1694-8.

23. Roelofs J, van Breukelen G, Sluiter J, Frings-Dresen MH, Goossens M, Thibault $P$, et al. Norming of the Tampa Scale for Kinesiophobia across pain diagnoses and various countries. Pain. 2011;152(5):1090-5.

24. Swinnen TW, Vlaeyen JWS, Dankaerts W, Westhovens R, de Vlam K. Activity limitations in patients with axial spondyloarthritis: a role for fear of movement and (re)injury beliefs. J Rheumatol. 2018;45(3):357-66.

25. Chan CY, Tsang HHL, Lau CS, Chung HY. Prevalence of depressive and anxiety disorders and validation of the Hospital Anxiety and Depression Scale as a screening tool in axial spondyloarthritis patients. Int J Rheum Dis. 2017;20(3):317-25.

26. Mease PJ, Goffe BS, Metz J, VanderStoep A, Finck B, Burge DJ. Etanercept in the treatment of psoriatic arthritis and psoriasis: a randomised trial. Lancet. 2000;356(9227):385-90.

27. Wolfe F, Clauw DJ, Fitzcharles MA, Goldenberg DL, Katz RS, Mease P, et al. The American College of Rheumatology preliminary diagnostic criteria for fibromyalgia and measurement of symptom severity. Arthritis Care Res (Hoboken). 2010;62(5):600-10.

28. International Association for the Study of Pain (IASP). Classification of Chronic Pain, Second Edition (Revised). http://www.iasp-pain.org/ PublicationsNews/Content.aspx?ltemNumber $=1673 \&$ navltemNumber $=677$. Accessed 4 Oct 2017. 
29. Slipman CW, Jackson HB, Lipetz JS, Chan KT, Lenrow D, Vresilovic EJ. Sacroiliac joint pain referral zones. Arch Phys Med Rehabil. 2000;81(3):334-8.

30. Landis JR, Koch GG. The measurement of observer agreement for categorical data. Biometrics. 1977;33(1):159-74.

31. Dougados M, Etcheto A, Molto A, Alonso S, Bouvet S, Daures JP, et al. Clinical presentation of patients suffering from recent onset chronic inflammatory back pain suggestive of spondyloarthritis: the DESIR cohort. Joint Bone Spine. 2015;82(5):345-51.

32. Lee W, Reveille JD, Davis JC Jr, Learch TJ, Ward MM, Weisman MH. Are there gender differences in severity of ankylosing spondylitis? Results from the PSOAS cohort. Ann Rheum Dis. 2007;66(5):633-8.

33. Baraliakos X, Landewé R, Hermann KG, Listing J, Golder W, Brandt J, et al. Inflammation in ankylosing spondylitis: a systematic description of the extent and frequency of acute spinal changes using magnetic resonance imaging. Ann Rheum Dis. 2005;64(5):730-4.

34. Blachier M, Coutanceau B, Dougados M, Saraux A, Bastuji-Garin S, Ferkal S, et al. Does the site of magnetic resonance imaging abnormalities match the site of recent-onset inflammatory back pain? The DESIR cohort. Ann Rheum Dis. 2013;72(6):979-85.

35. Szadek KM, Hoogland PV, Zuurmond WW, de Lange JJ, Perez RS. Nociceptive nerve fibers in the sacroiliac joint in humans. Reg Anesth Pain Med. 2008;33(1):36-43.

36. Ford KR, Myer GD, Hewett TE. Valgus knee motion during landing in high school female and male basketball players. Med Sci Sports Exerc. 2003; 35(10):1745-50.

37. Jacques $\mathrm{P}$, Lambrecht $\mathrm{S}$, Verheugen E, Pauwels E, Kollias G, Armaka M, et al. Proof of concept: enthesitis and new bone formation in spondyloarthritis are driven by mechanical strain and stromal cells. Ann Rheum Dis. 2014;73(2):437-45.

38. Tournadre A, Pereira B, Lhoste A, Dubost JJ, Ristori JM, Claudepierre P, et al. Differences between women and men with recent-onset axial spondyloarthritis: results from a prospective multicenter French cohort. Arthritis Care Res (Hoboken). 2013;65(9):1482-9.

39. Ramonda R, Lorenzin M, Lo Nigro A, Vio S, Zucchetta P, Frallonardo P, et al. Anterior chest wall involvement in early stages of spondyloarthritis: advanced diagnostic tools. J Rheumatol. 2012;39(9):1844-9.

40. Wendling D, Prati C, Demattei C, Loeuille D, Richette P, Dougados M. Anterior chest wall pain in recent inflammatory back pain suggestive of spondyloarthritis: data from the DESIR cohort. J Rheumatol. 2013;40(7):1148-52.

41. Bogduk N. The innervation of the lumbar spine. Spine (Phila Pa 1976). 1983; 8(3):286-93

42. Fillingim RB, King CD, Ribeiro-Dasilva MC, Rahim-Williams B, Riley JL 3rd. Sex, gender, and pain: a review of recent clinical and experimental findings. $J$ Pain. 2009;10(5):447-85.

43. Incel NA, Erdem HR, Ozgocmen S, Catal SA, Yorgancioglu ZR. Pain pressure threshold values in ankylosing spondylitis. Rheumatol Int. 2002;22(4):148-50.

44. Wu Q, Inman RD, Davis KD. Tumor necrosis factor inhibitor therapy in ankylosing spondylitis: differential effects on pain and fatigue and brain correlates. Pain. 2015;156(2):297-304.

45. Gerecz-Simon EM, Tunks ER, Heale JA, Kean WF, Buchanan WW. Measurement of pain threshold in patients with rheumatoid arthritis, osteoarthritis, ankylosing spondylitis and healthy controls. Clin Rheumatol. 1989;8(4):467-74.

46. Bagnato G, De Andres I, Sorbara S, Verduci E, Corallo G, Ferrera A, et al. Pain threshold and intensity in rheumatic patients: correlations with the Hamilton Depression Rating Scale. Clin Rheumatol. 2015;34(3):555-61.

47. Kaya A, Ozgocmen S, Kamanli A, Aydogan R, Yildirim A, Ardicoglu O. Evaluation of a quantitative scoring of enthesitis in ankylosing spondylitis. J Clin Rheumatol. 2007;13(6):303-6.

48. Bönisch A, Ehlebracht-König I. The BASDAI-D - an instrument to defining disease status in ankylosing spondylitis and related diseases [in German]. Z Rheumatol. 2003;62(3):251-63.

49. Kilic E, Kilic G, Akgul O, Ozgocmen S. Discriminant validity of the Ankylosing Spondylitis Disease Activity Score (ASDAS) in patients with non-radiographic axial spondyloarthritis and ankylosing spondylitis: a cohort study. Rheumatol Int. 2015;35(6):981-9.

50. van der Horst-Bruinsma IE, Zack DJ, Szumski A, Koenig AS. Female patients with ankylosing spondylitis: analysis of the impact of gender across treatment studies. Ann Rheum Dis. 2013;72(7):1221-4.

51. Fernandez-Espartero C, de Miguel E, Loza E, Tomero E, Gobbo M, Descalzo $M A$, et al. Validity of the ankylosing spondylitis disease activity score (ASDAS) in patients with early spondyloarthritis from the Esperanza programme. Ann Rheum Dis. 2014;73(7):1350-5.

\section{Ready to submit your research? Choose BMC and benefit from:}

- fast, convenient online submission

- thorough peer review by experienced researchers in your field

- rapid publication on acceptance

- support for research data, including large and complex data types

- gold Open Access which fosters wider collaboration and increased citations

- maximum visibility for your research: over $100 \mathrm{M}$ website views per year

At BMC, research is always in progress.

Learn more biomedcentral.com/submissions 